\title{
EFFECT OF POROSITY AND EVAPORATION TEMPERATURE ON THE PERFORMANCE OF A REFRIGERATION SYSTEM USING POROUS EVAPORATOR: R422A CASE STUDY
}

\author{
Mohammad Tarawneh \\ Associate Professor \\ Mechanical Engineering Department \\ The Hashemite University, Zarqa 13115 Jordan \\ Tel: +96253903333 \\ Fax: +96253903338 \\ mohammad.tarawneh@hu.edu.jo
}

\begin{abstract}
The effect of using porous materials in flow passages of refrigerants during the evaporation process on the performance of a refrigeration systems is experimentally investigated. The effect of changing the evaporation temperature and the evaporator porosity on the behavior of the refrigeration cycle is studied. Refrigeration capacity, condenser capacity, power of compression, coefficient of performance, volumetric refrigeration capacity, compressor discharge temperature, pressure drop and the power consumption per ton of refrigeration were studied for different evaporation temperatures and different evaporator porosities. Empty tube evaporator and porous tube evaporator with porosities of $48 \%, 43 \%$ and $39 \%$ were used during the experimental tests. Small metallic spheres were used as porous inserts in the evaporator. The evaporation temperature was changed in the range of $\left(-31.5^{\circ} \mathrm{C}\right.$ to $\left.-19.1^{\circ} \mathrm{C}\right)$. Condensing temperature, degree of subcooling and degree of superheating were kept constants at $38^{\circ} \mathrm{C}, 6^{\circ} \mathrm{C}, 6^{\circ} \mathrm{C}$, respectively. The performance analysis showed that, the refrigeration capacity, condenser capacity, volumetric refrigeration capacity as well as coefficient of performance of the refrigeration cycle can be enhanced by increasing the evaporation temperature and by decreasing the evaporator porosity. The Refrigeration capacity, condenser capacity, coefficient of performance, volumetric refrigeration capacity when using R422A as refrigerant in the refrigeration cycle showed percentages of increase of about $166 \%, 48.9 \%, 283 \%, 64.7 \%$, respectively when changing the porosity of the evaporator from empty tube evaporator to $39 \%$ porous evaporator and increasing the evaporation temperature from $\left(-31.5^{\circ} \mathrm{C}\right.$ to $\left.-19.1^{\circ} \mathrm{C}\right)$. Low values of compressor power consumption and power consumption per ton of refrigeration were recorded at lower evaporator porosity and higher evaporation temperature. Low compressor discharge temperatures were detected at higher evaporation temperature and lower evaporator porosity.
\end{abstract}

KEY WORDS: Evaporation, Performance enhancement, Porosity, R422A, Refrigerants, Refrigeration.

\section{INTRODUCTION}

Enhancement of the performance of the refrigeration systems is a major goal of many researchers in the world of refrigeration and air conditioning systems. The design of evaporators and the magnitude of evaporation temperature play a big rule in the improvement of the performance of the refrigeration cycle. Y. Ould-Amera et al (1998) [1], studied the forced convection cooling enhancement by use of porous materials. R. Cabello, et al (2004) [2], conducted an experimental evaluation of a vapor compression plant performance 
using R134a, R407C and R22 as working fluids. Lee H-S et al (2006) [3], studied the condensing heat transfer and pressure drop characteristics of different hydrocarbon refrigerants. Zhang X et al (2008) [4], performed and experimental investigation on the heat transfer characteristics for evaporation of R417A flowing inside horizontal smooth and internally grooved tubes. A.S. Dalkilica et al (2010) [5], conducted an experimental comparative performance study on vapor compression refrigeration system using various alternative refrigerants. Abdullah A.A.A. Al-Rashed (2011) [6], studied the effect of evaporator temperature on the performance of vapor compression refrigeration cycle. A performance comparative evaluation of vapor compression refrigeration system using various alternative refrigerants was conducted by $\mathrm{A}$. Baskaran et al (2012) [7]. B.O. Bolaji et al (2015) [8] conducted a performance assessment of three eco-friendly refrigerant mixtures as R22 alternatives in refrigeration systems. Mitesh M. et al(2015)[9] investigated the performance of different alternative hydrocarbon refrigerants of R22 refrigerant. A heat transfer improvement study and pressure drop performance evaluation for R417A flow boiling in internally grooved tubes were performed by Zhang $X$ et al (2015) [10]. A. Baskaran et al (2015) [11] investigated the performance of domestic refrigerator when using new eco-friendly refrigerant mixture as an alternative to R134a.). A theoretical performance study of vapor compression refrigeration system using different refrigerant mixtures as alternatives to R22 was conducted by sharmas valishaika et al (2017) [12]. Performance investigation of refrigerants R290 and R134a as alternatives to R22 was done by R. S. Powade et al (2018) [13]. Mohammad Tarawneh (2019) [14]. conducted a Performance study on the evaporation and pressure drop of low-temperature refrigerant blends in porous media. The Combined Effect of Using Subcooling Regenerator and Porous Evaporator on the Performance of Refrigeration System was investigated by Mohammad Tarawneh (2019) [15]. In this experimental performance study attention is focused on the effect of inserting porous materials in the tubes of the evaporator on the different performance parameters. On the other hand, the effect of changing the evaporation temperature on the refrigeration cycle performance is also considered. Refrigeration capacity, condenser capacity, power of compression, coefficient of performance, volumetric refrigeration capacity, compressor discharge temperature, pressure drop and power consumption per ton of refrigeration were studied for different evaporation temperatures and different evaporator porosities.

\section{EXPERIMENTS}

The schematic diagram of the test rig used during this experimental work is shown in Fig. 1. The test rig. Consists of porous evaporator of $19 \mathrm{~mm}$ inner diameter horizontal tubes and an empty condenser of $19 \mathrm{~mm}$ inner diameter horizontal tubes. Small metallic spheres of different sizes were used as porous inserts in the flow passages of the refrigerant in the evaporator. Three different samples of metallic spheres with porosities of $39 \%, 43 \%$ and $48 \%$ were used during the tests. Hermetic compressor type of $1 \mathrm{hp}$ is used during the tests. A Coriolis liquid mass flow meter is used to measure the mass flow rate in the tested refrigeration cycle. A précised thermostatic expansion valve is used to regulate the rate at which liquid refrigerant flows into the evaporator. k-type thermocouples were used to detect the temperature of the refrigerant during the tests. Pressure transducers are used to measure the pressure of the working refrigerant at different points in the cycle. Data Acquisition system of (model SCXI 1000, manufactured by National Instruments Company) is used to process the measured data. Computer and printer were used to display the measured parameters. Refrigerant R422A is used as working fluid during all tests. Condensing temperature as well as degree of subcooling and degree of superheating were kept constants at $38^{\circ} \mathrm{C}, 6^{\circ} \mathrm{C}, 6^{\circ} \mathrm{C}$, respectively during the experiments. Evaporation temperatures were varied from $-31.5^{\circ} \mathrm{C}$ to $-19.1{ }^{\circ} \mathrm{C}$. Table. 1 shows the thermophysical properties of the used refrigerant (R422A) which, were selected from Bitzer Refrigerant Report (2012) [16], [17]. 


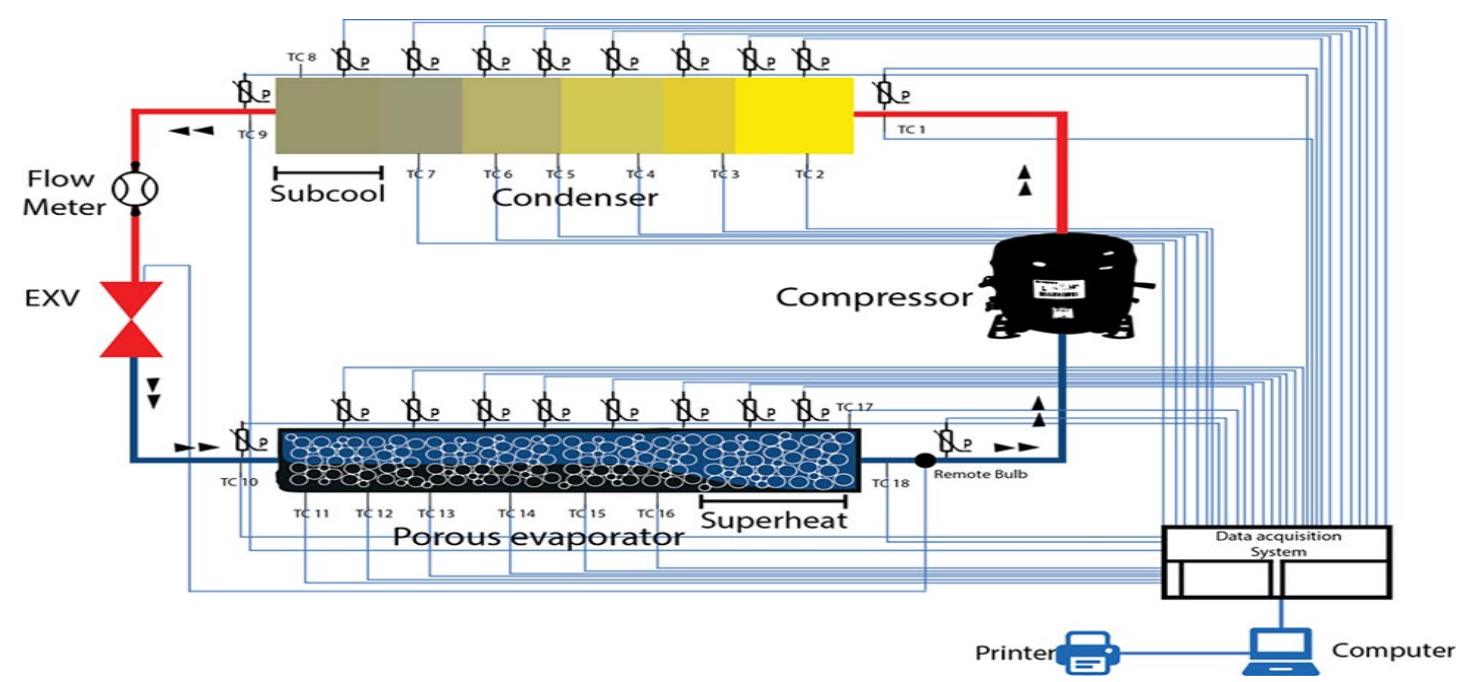

Fig. 1. Schematic diagram of experimental test rig.

Table.1 Thermophysical properties of R422A

\begin{tabular}{|c|c|c|c|c|}
\hline $\begin{array}{c}\text { Critical } \\
\text { pressure } \\
\text { (bar) }\end{array}$ & $\begin{array}{c}\text { Critical } \\
\text { Temperature } \\
\left({ }^{\circ} \mathrm{C}\right)\end{array}$ & ODP & GWP & Composition \\
\hline 37.5 & 71.8 & 0 & 3144 & $\begin{array}{c}\mathrm{R}-125 / 134 \mathrm{a} / 600 \mathrm{a} \\
(85.1 \% / 11.5 \% / 3.4 \%)\end{array}$ \\
\hline
\end{tabular}

\section{CYCLE ANALYSIS}

The P-h diagram of the studied refrigeration cycle is shown in Fig. 2. Refrigeration capacity, condenser capacity, power of compression, coefficient of performance, volumetric refrigeration capacity, compressor discharge temperature, pressure drop and the power consumption per ton of refrigeration were studied for different evaporation temperatures and different evaporator porosities. Referring to Fig.2, the refrigeration capacity $(R C)$ in $(\mathrm{kW})$ can be calculated according to the following equation:

$$
R C \stackrel{m^{\prime}}{m_{\text {ref }}}(h 1-h 4)
$$

Where: $\dot{m}_{r e f}$ is the mass flow rate of refrigerant in $(\mathrm{kg} / \mathrm{s}), h 1$ and $h 4$ are enthalpies of the refrigerant in $(\mathrm{kJ} / \mathrm{kg})$ at exit and inlet of the evaporator, respectively [18]. The condenser capacity (CC) in (kW) is calculated according to following formula:

$C C=m_{r e f}^{*}(h 2-h 3)$

Where: $h 2$ and $h 3$ are enthalpies of the refrigerant in $(\mathrm{kJ} / \mathrm{kg})$ at inlet and exit of the condenser, respectively. The power of compression in $(\mathrm{kW})$ can be found according to the following equation:

$$
P C=m_{\text {ref }}^{*}(h 2-h 1)
$$

Where: $h 1$ and $h 2$ are enthalpies of the refrigerant in $(\mathrm{kJ} / \mathrm{kg})$ at exit and inlet of the compressor, respectively [18]. The cycle coefficient of performance can be found using the following relation:

$$
C O P=\frac{h 1-h 4}{h_{2}-h_{1}}
$$


The volumetric refrigeration capacity $(\mathrm{VRC})$ in $\left(\mathrm{kJ} / \mathrm{m}^{3}\right)$ can be found according to following equation:

$$
V R C=\frac{h 1-h 4}{\text { ves }}
$$

The pressure drop (PD) in $(\mathrm{kPa})$ in porous and empty tube evaporators is found according to the following relation:

$P D=P 4-P 1$

where: vcis the specific volume of refrigerant at inlet of the compressor.

The power consumption per ton of refrigeration (PCPTR) in (kW/TR) can be found according to the following relation:

PCPTR $=\frac{3.5 P C}{R C}$

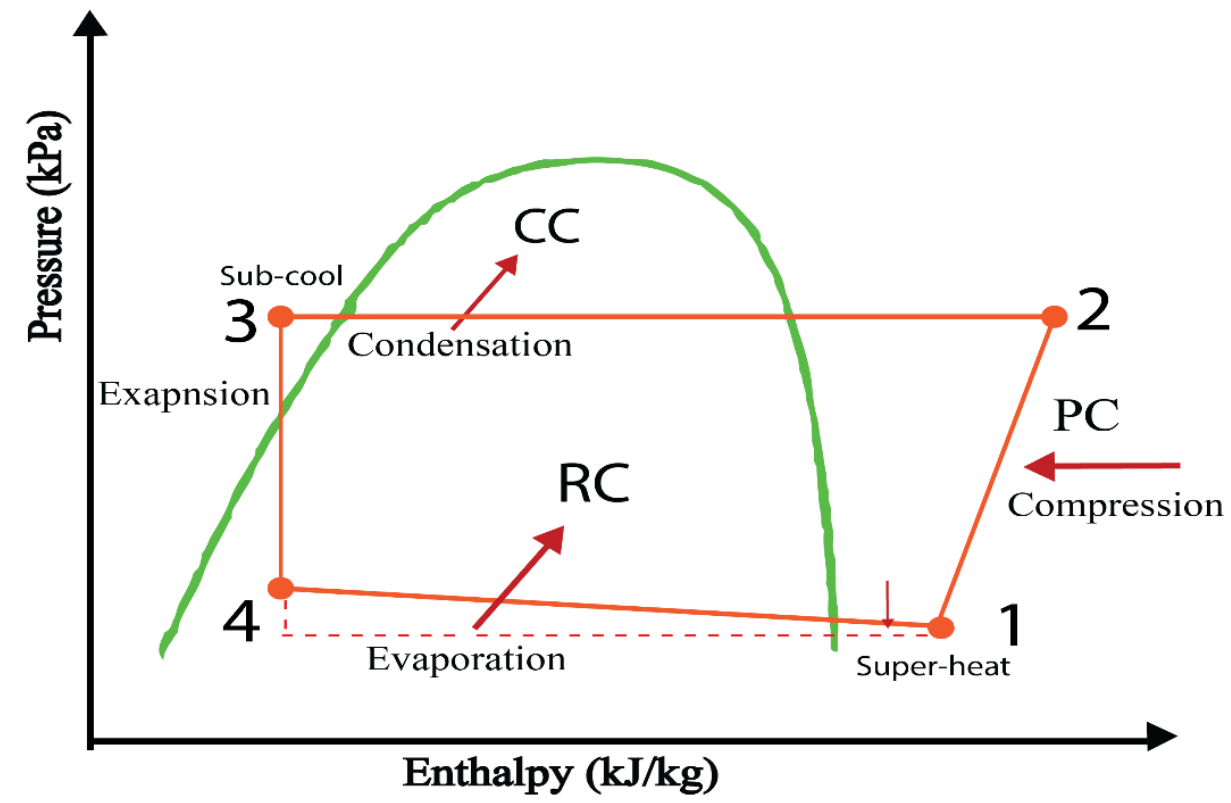

Fig.2. P-h Diagram of the refrigeration cycle

\section{RESULTS AND DISCUSSION}

The variations of refrigeration capacity, volumetric refrigeration capacity and coefficient of performance with evaporation temperature and evaporator porosity are shown in Fig. 3, Fig. 4 and Fig. 5, respectively. The Refrigeration capacity, volumetric refrigeration capacity and coefficient of performance, when using $\mathrm{R} 422 \mathrm{~A}$ as refrigerant in the refrigeration cycle showed percentages of increase of about $166 \%, 64.7 \%$ and $283 \%$, respectively when changing the porosity of the evaporator from empty tube evaporator to $39 \%$ porous evaporator and increasing the evaporation temperature from $\left(-31.5^{\circ} \mathrm{C}\right.$ to $\left.-19.1{ }^{\circ} \mathrm{C}\right)$. The variation of condenser capacity in $(\mathrm{kW})$ with evaporation temperature and evaporator porosity is shown in Fig. 6. A percent increase of about $48.9 \%$ in $\mathrm{CC}$ was noticed at evaporation temperature of $-19.1^{\circ} \mathrm{C}$ and evaporator porosity of $39 \%$. The power consumption per ton of refrigeration as function of evaporator porosity and evaporation temperature is drawn in Fig. 7. It can be noticed from figure 7 that, PCPTR is decreased by decreasing porosity and by increasing evaporation temperature. The relationship between the calculated power of compression and evaporation temperature for different evaporator porosities is 
depicted in Fig. 8. It is very clear from this figure that the power of compression can be decreased by increasing evaporation temperature and by decreasing evaporator porosity.

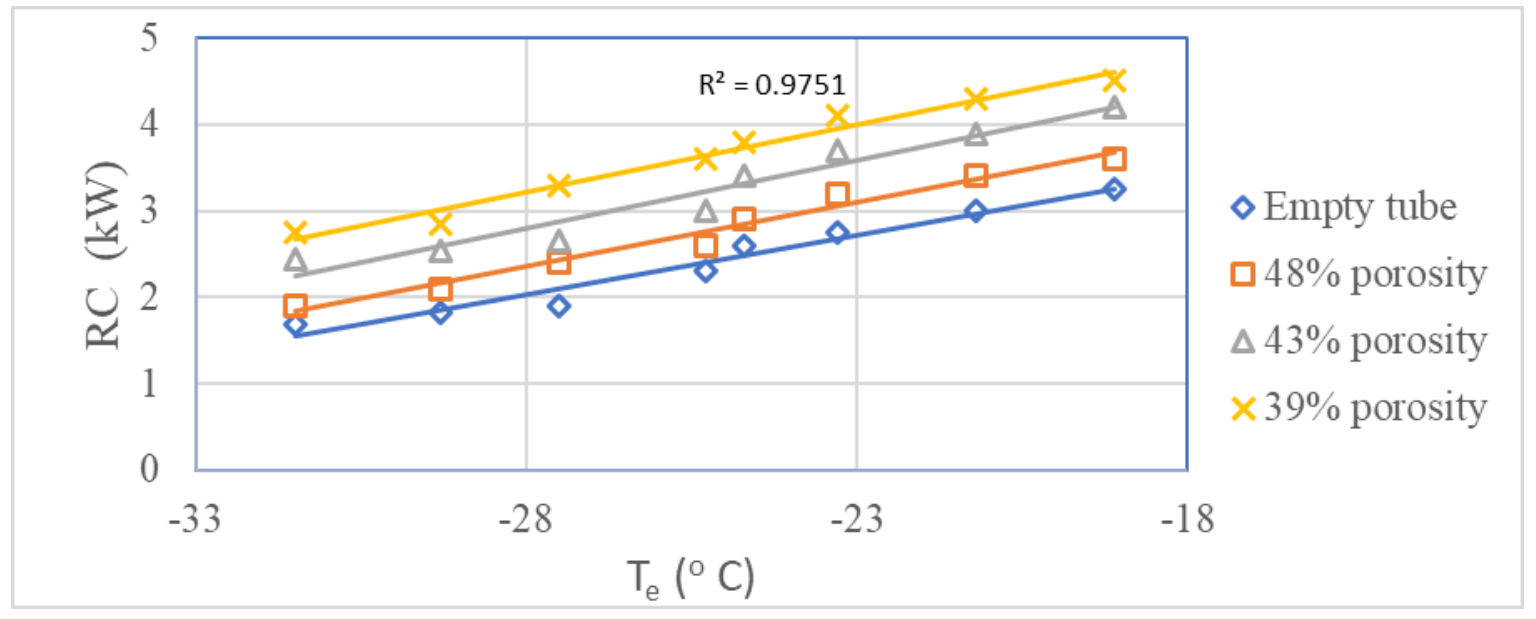

Fig. 3. Variation of $\mathrm{RC}$ with $\mathrm{T}_{\mathrm{e}}$ for different evaporator porosities

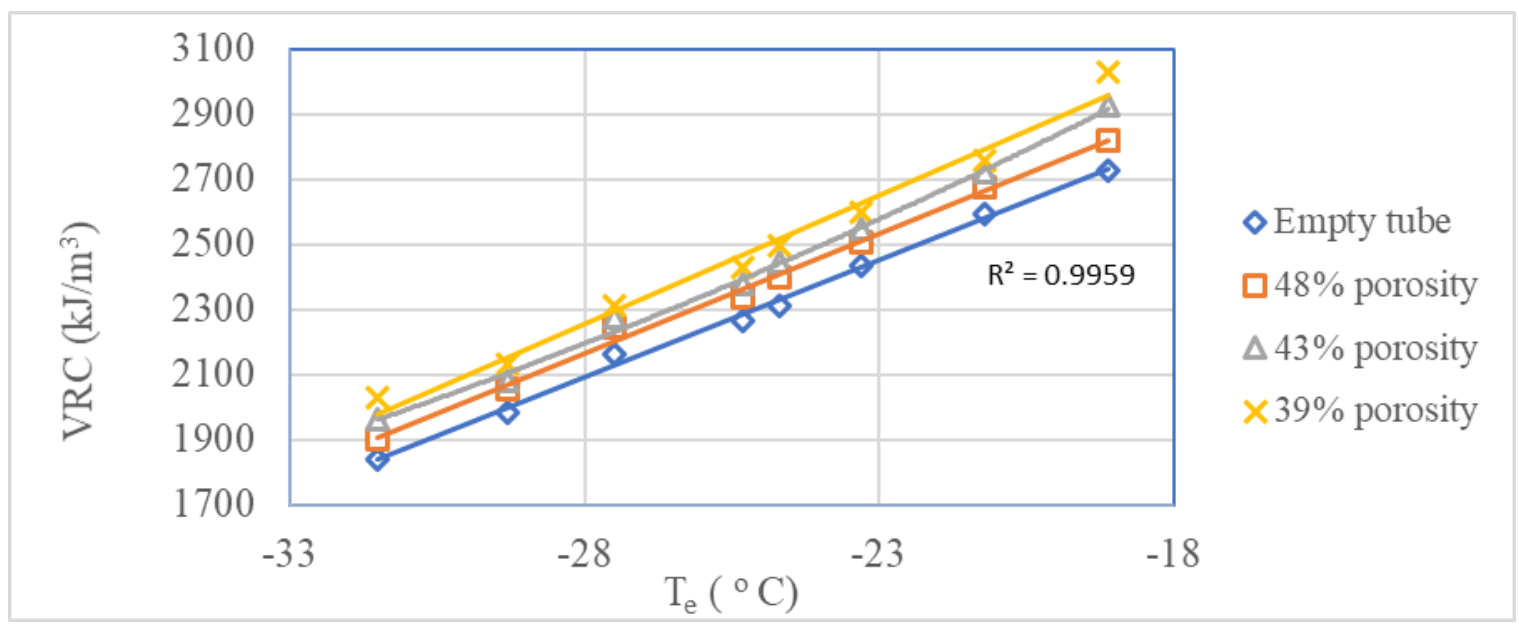

Fig. 4. Variation of VRC with $\mathrm{T}_{\mathrm{e}}$ in $\left({ }^{\circ} \mathrm{C}\right)$ for different evaporator porosities 


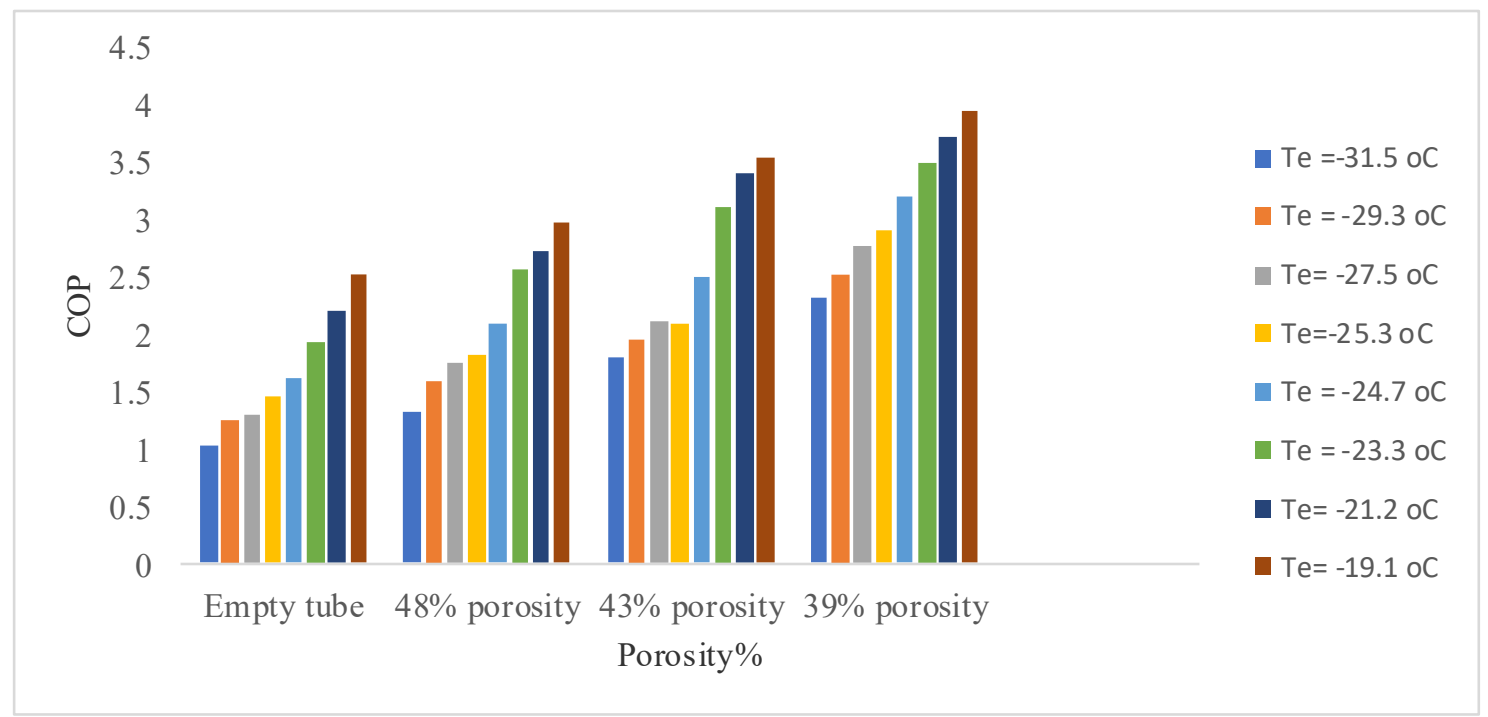

Fig. 5. Variation of $\mathrm{COP}$ with $\mathrm{T}_{\mathrm{e}}$ in $\left({ }^{\circ} \mathrm{C}\right)$ for different evaporator porosities

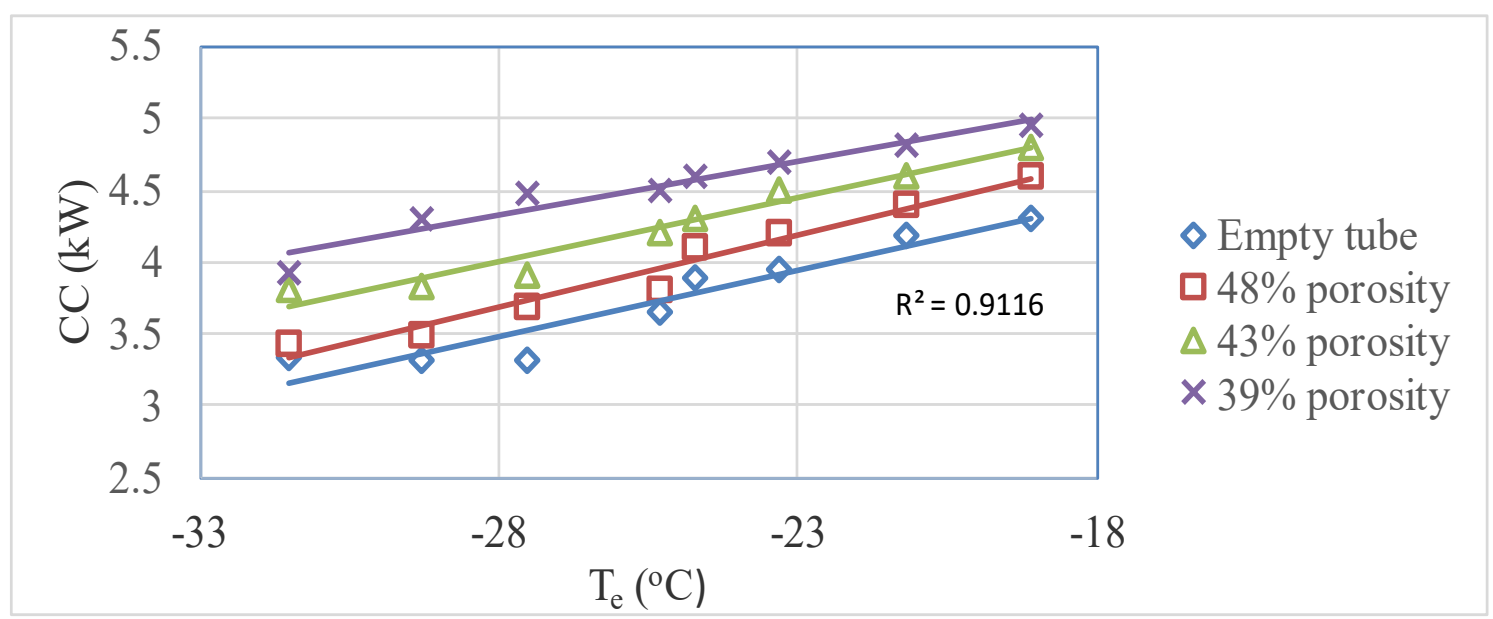

Fig. 6. Variation of $\mathrm{CC}$ with $\mathrm{T}_{\mathrm{e}}$ in $\left({ }^{\circ} \mathrm{C}\right)$ for different evaporator porosities

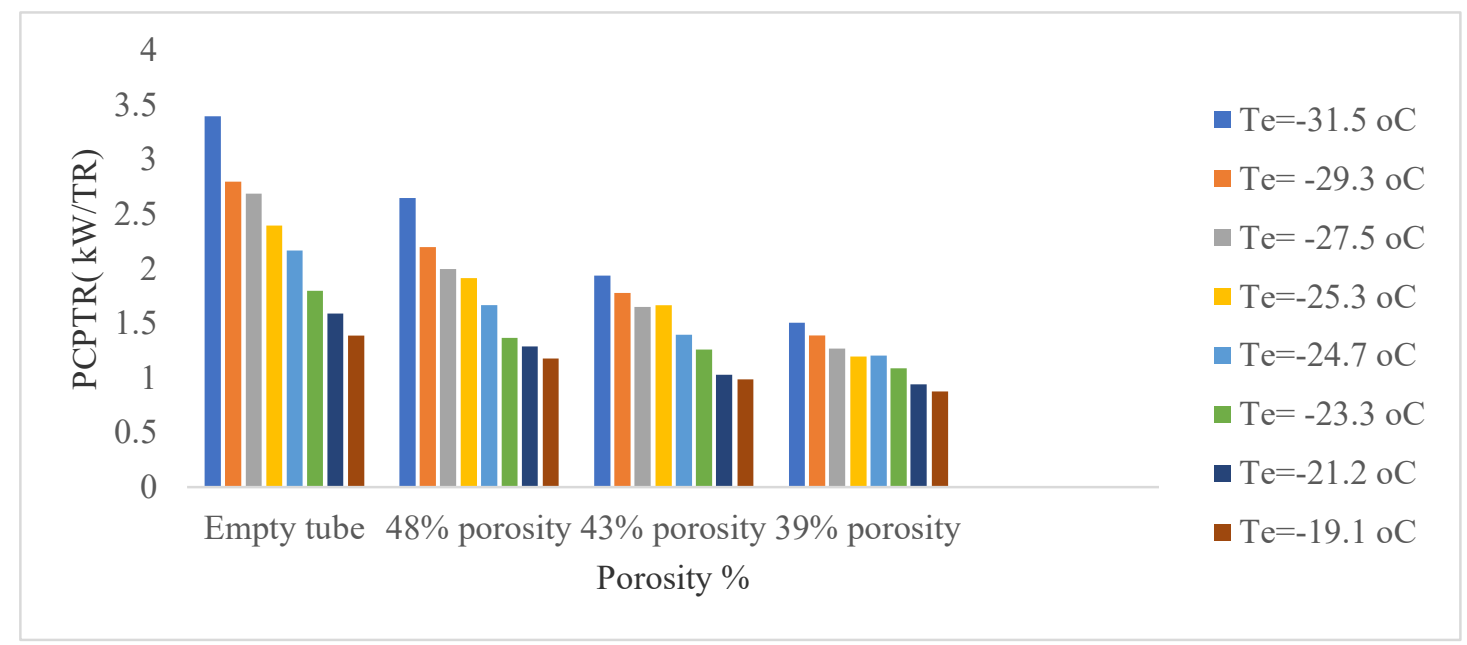

Fig. 7. Variation of PCPTR with $\mathrm{T}_{\mathrm{e}}$ in $\left({ }^{\circ} \mathrm{C}\right)$ for different evaporator porosities 


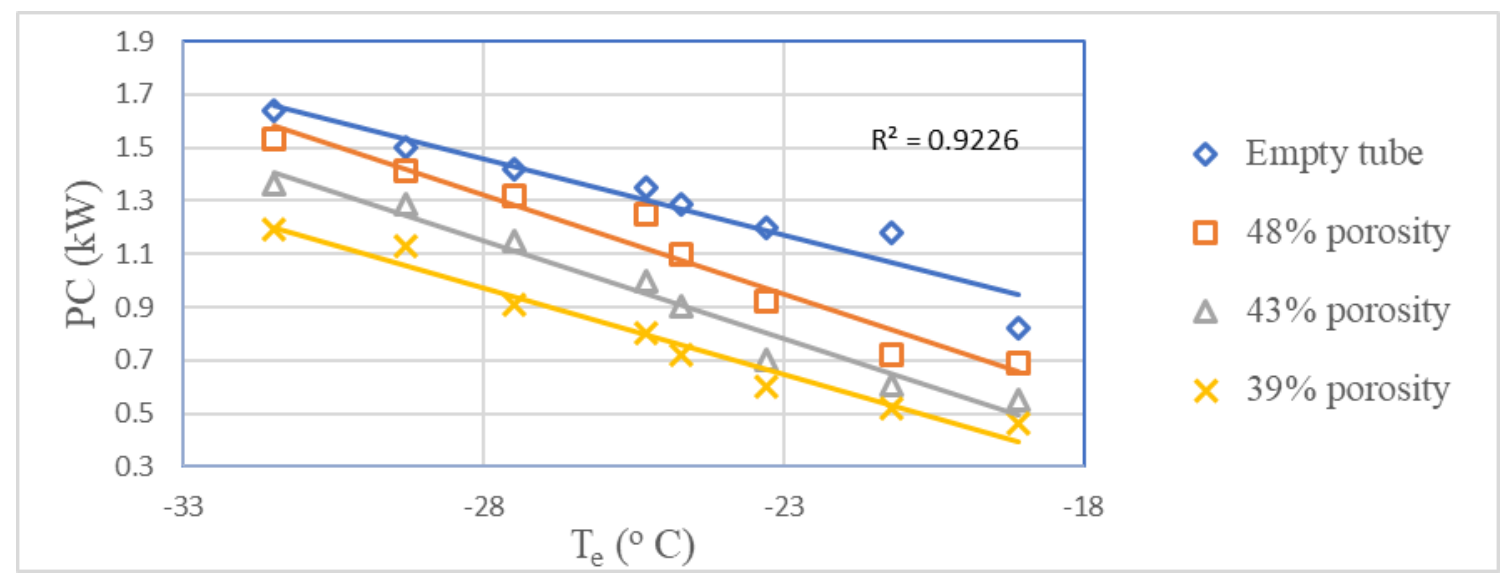

Fig. 8. Variation of $\mathrm{PC}$ with $\mathrm{T}_{\mathrm{e}}$ in $\left({ }^{\circ} \mathrm{C}\right)$ for different evaporator porosities

The deviation between the actual power of compression PCa and the calculated power of compression PCc when, using empty tube evaporator is shown in Fig. 9.It is clear from this figure that, the actual power of compression is lower at lower evaporation temperature and it has an optimum value at a specified evaporation temperature but the calculated $\mathrm{PC}$ is decreased by increasing the evaporation temperature.

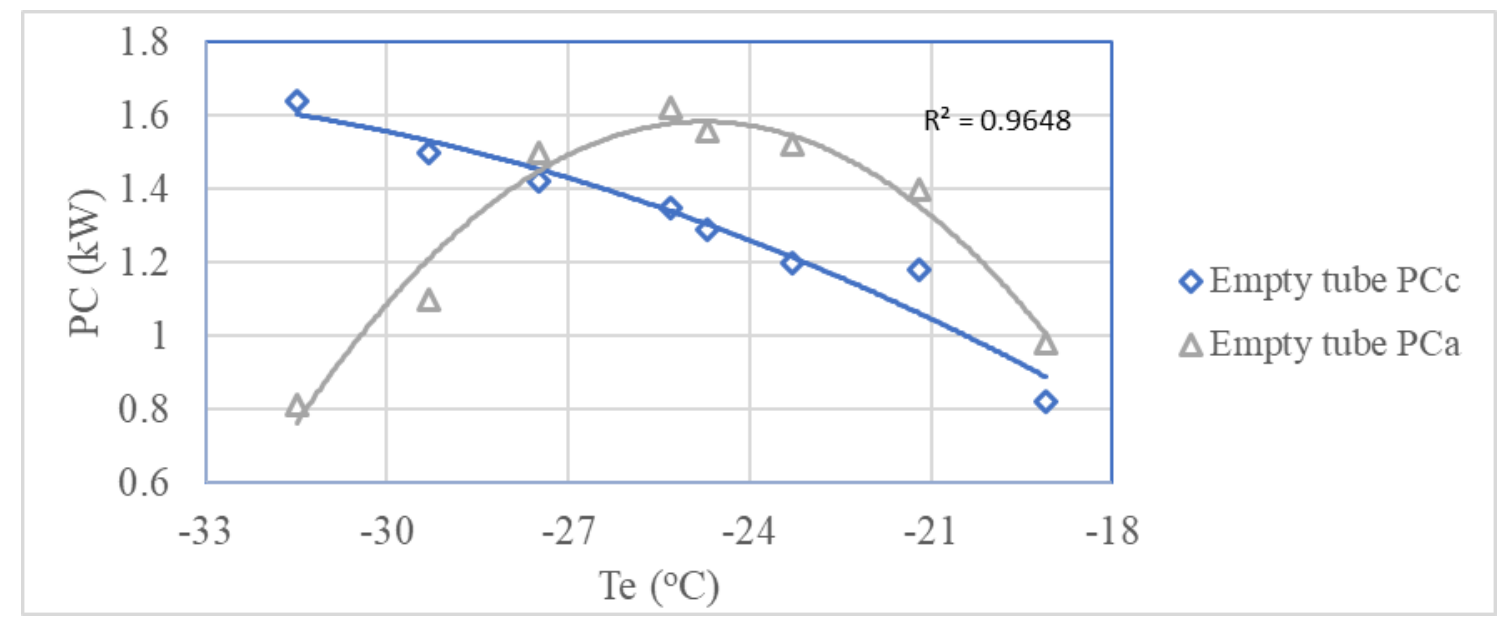

Fig. 9. Variation of $\mathrm{PCc}$ and $\mathrm{PCa}$ with $\mathrm{T}_{\mathrm{e}}$ in $\left({ }^{\circ} \mathrm{C}\right)$ for empty tube evaporator

The variation of the actual compression power in $(\mathrm{kW})$ with evaporation temperature when using empty and porous tube evaporator is shown in Fig. 10. It can be concluded from this figure that, PCa is lower when using porous tube evaporator with an average percent decrease of about $45 \%$ when using porous evaporator of $48 \%$ porosity. The compressor discharge temperature versus evaporation temperature and compression ratio is shown in Figs. $(11,12)$.It can be noticed from these figures that discharge temperature is decreased by decreasing porosity and by increasing evaporation temperature and it is increased by increasing compression ratio $\left(\mathrm{r}_{\mathrm{c}}\right)$. The pressure drop through the porous and empty evaporator as function of evaporation temperature is shown in Fig. 13. The pressure drop is inversely proportional with evaporation temperature and evaporator porosity as it can be noticed from Fig. 13. 


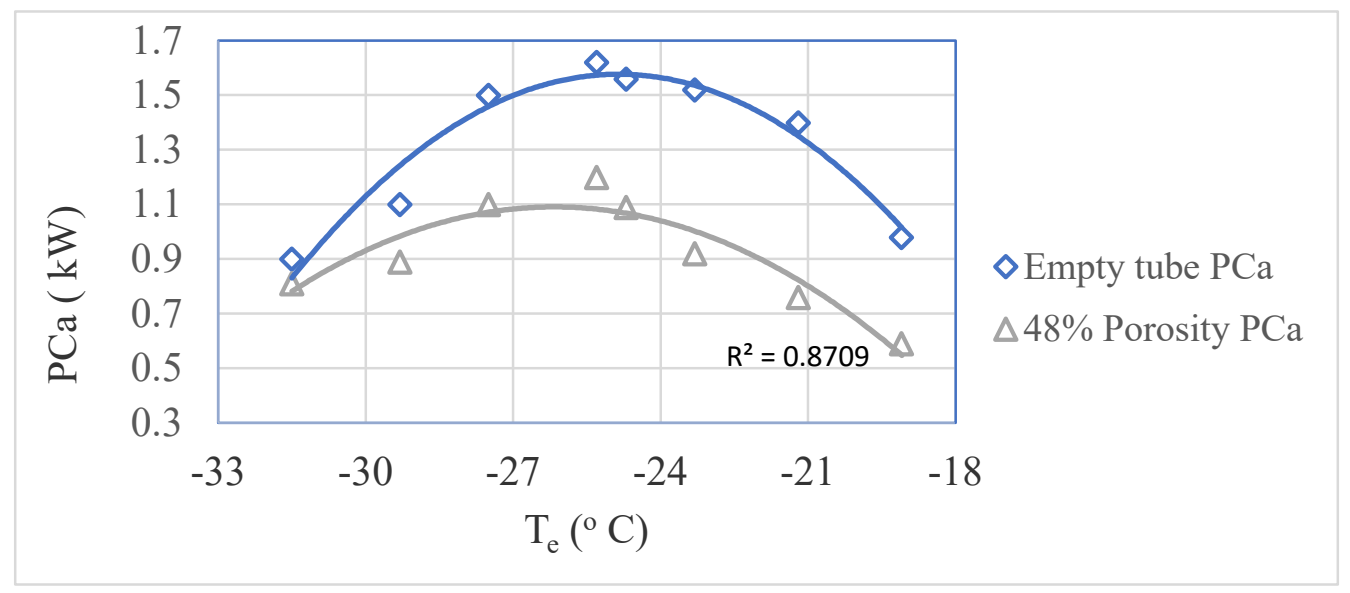

Fig. 10. Variation of $\mathrm{PCa}$ with $\mathrm{T}_{\mathrm{e}}$ in $\left({ }^{\circ} \mathrm{C}\right)$ for different evaporator porosities

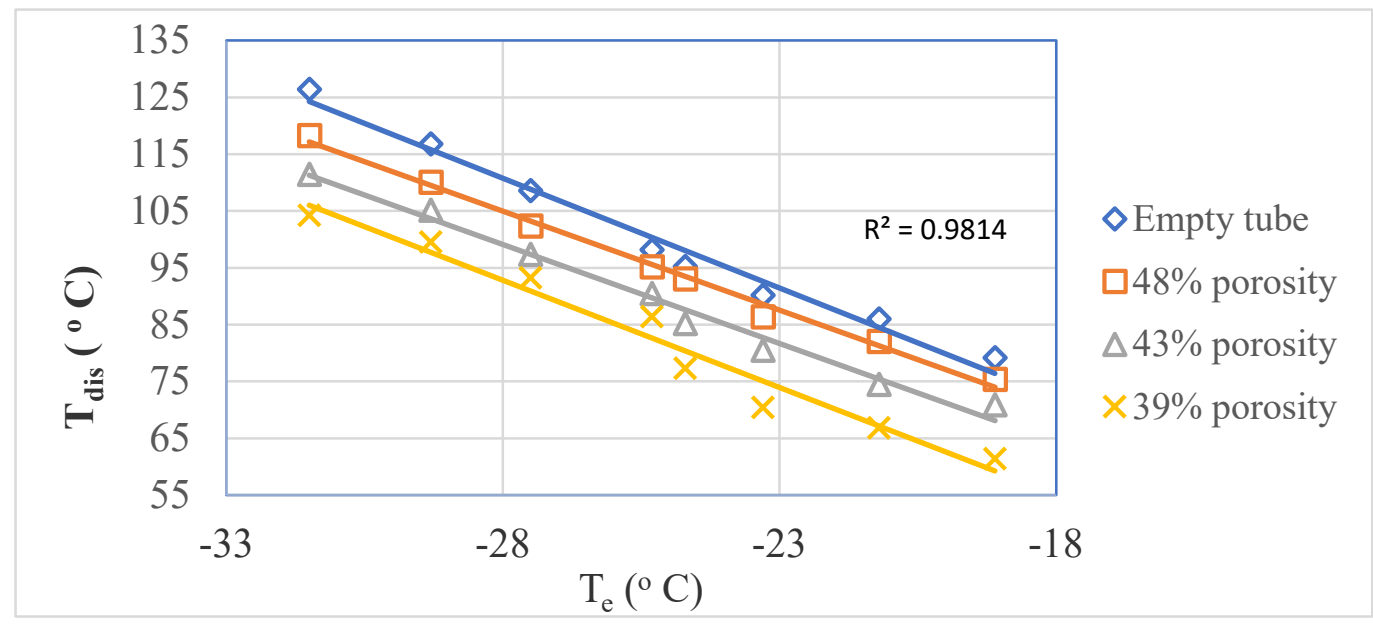

Fig. 11. Variation of compressor discharge temperature with $\mathrm{T}_{\mathrm{e}}$ for different porosities

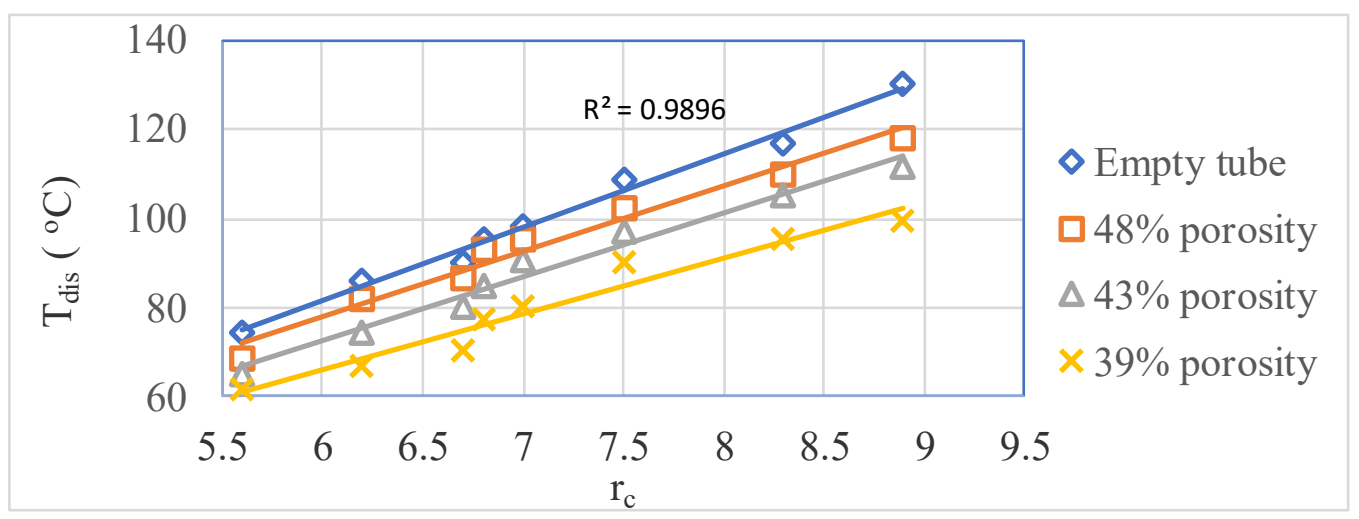

Fig. 12. Variation of compressor discharge temperature with Compression ratio for different porosities 


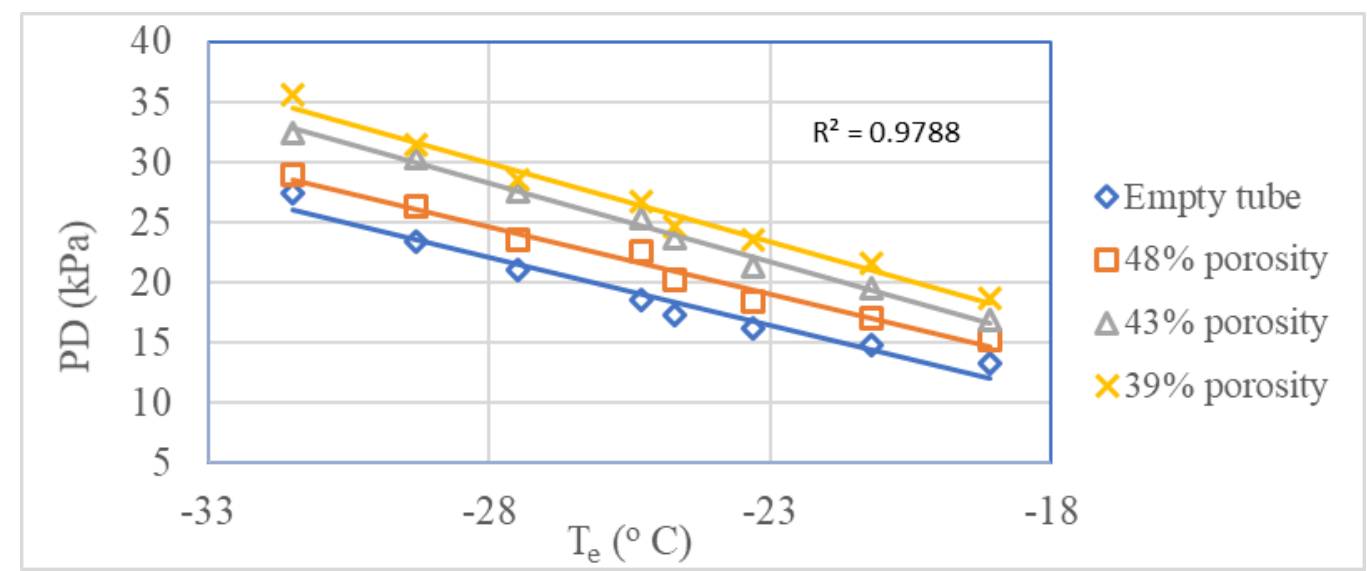

Fig. 13. Variation of pressure drop with $\mathrm{T}_{\mathrm{e}}$ for different evaporator porosities

\section{CONCLUSIONS}

In this experimental work ,two effective techniques are used to enhance the performance of a refrigeration system,namely: the use of porous evaporator and the increase of the evaporating temperature.Refrigeration capacity, volumetric refrigeration capacity and coefficient of performance showed avaluble increase when increasing the evaporation temperature and decreasing the evaporator porosity. The condensation capacity is increased by increasing evaporation temperature. A percent increase of about $48.9 \%$ in CC was noticed at evaporation temperature of $-19.1^{\circ} \mathrm{C}$ and evaporator porosity of $39 \%$. A percentage increase of about $283 \%$ in COP of R422A was detected for $39 \%$ porous evaporator and $-19.1^{\circ} \mathrm{C}$ evaporating temperature. It can be concluded also, that the actual power of compression is lower when using porous tube evaporator at higher evaporating temperatures. This experimental investigation showed that, the compressor discharge temperature can be decreased by decreasing porosity and by increasing evaporation temperature and it is increased by increasing compression ratio $\left(r_{c}\right)$. The pressure drop in the porous evaporator is increased by increasing the evaporation temperature and decreasing the evaporator porosity. The results of this experimental work revealed that, the power consumption per ton of refrigeration (PCPTR) can be decreased by decreasing porosity and by increasing evaporation temperature.

\section{UNCERTAINITY ANALYSIS}

The experimental calculated parameters are related to different measured parameters according to the following equations:

$$
\begin{aligned}
& R C=f\left(T e, P e, \dot{m}_{\text {ref }}\right) \\
& C O P=f\left(T e, P e, \dot{m}_{\text {ref }}\right) \\
& P C=f\left(T e, P e, T c, \dot{m}_{r e f}\right) \\
& C C=f\left(P C, T c, \dot{m}_{r e f}\right) \\
& P C P T R=f\left(T e, P e, T c, \dot{m}_{r e f}\right) \\
& V R C=f\left(T e, P e, \dot{m}_{r e f}\right)
\end{aligned}
$$

where, Te, Pe and $\mathrm{Tc}$ are evaporation temperature, evaporation pressure and condensing temperature, respectively. 
The uncertainties of the above calculated parameters are functions of the uncertainties of $\mathrm{Te}, \mathrm{Pe}, \mathrm{Tc}$ and $\dot{m}_{r e f}$. A classical or basic uncertainty analysis is executed and the resulted values are tabulated in table 2 . The sensitivity of each calculated parameter is found by plotting these parameters against the different variables. The slope of the resulted curve represents the partial derivative of the calculated parameter of the refrigerant with respect to each of the different variables mentioned in equations from (8-13).

Table 2: Uncertainty Data

\begin{tabular}{|l|l|l|}
\hline \multicolumn{2}{|l|}{ Experimental parameter } & Uncertainty \\
\hline \multirow{5}{*}{ Measured Parameters } & $\begin{array}{l}\text { Mass flow rate }(\mathrm{kg} / \mathrm{s}) \\
\text { (mass flow-meter reading) in }(\mathrm{kg} / \mathrm{s})\end{array}$ & $\pm 0.09 \mathrm{~kg} / \mathrm{min}$ \\
\cline { 2 - 3 } & Pressure transducer reading in $(\mathrm{kPa})$ & $\pm 0.0 .8 \mathrm{bar}$ \\
\cline { 2 - 3 } & $\begin{array}{l}\text { Temperature }\left({ }^{\circ} \mathrm{C}\right) \\
\text { (Thermocouple reading) }\end{array}$ & \multirow{2}{*}{ $\left.\pm 0.5^{\circ} \mathrm{C}\right)$} \\
\cline { 2 - 3 } & $\begin{array}{l}\text { Actual compression power in }(\mathrm{kW}) \\
\text { Electricity meter reading }(\mathrm{kW}-\mathrm{hr})\end{array}$ & $\pm 0.028(\mathrm{~kW}-\mathrm{hr})$ \\
\hline \multirow{5}{*}{ Calculated Parameters } & Refrigeration capacity $(\mathrm{RC})$ in $(\mathrm{kW})$ & $\pm 0.075 \mathrm{~kW}$ \\
\cline { 2 - 3 } & COP & \pm 0.080 \\
\cline { 2 - 3 } & PCPTR $(\mathrm{kW} /$ ton) & $\pm 0.19(\mathrm{~kW} / \mathrm{ton})$ \\
\cline { 2 - 3 } & Power of Compression $(\mathrm{PC})$ in $((\mathrm{kW})$ & $\pm 0.02 \mathrm{~kW}$ \\
\cline { 2 - 3 } & Condenser Capacity $(\mathrm{CC})$ in $(\mathrm{kW})$ & $\pm 0.032 \mathrm{~kW}$ \\
\cline { 2 - 3 } & VRC in $\left(\mathrm{kJ} / \mathrm{m}^{3}\right)$ & \\
\hline
\end{tabular}

\section{NOMENCLATURE}

\section{C: Centigrade}

CC: Condensing Capacity $(\mathrm{kW})$

COP: Coefficient of Performance

GWP: Global Warming Potential

$\mathrm{h}$ : Enthalpy( $\mathrm{kJ} / \mathrm{kg})$

kW: Kilowatts

ODP: Ozone Depletion Potential

PC: Power of Compression (kW)

letter

o: Degree
PCc: Calculated Power of Compression (kW)

PCPTR: Power Consumption Per Ton of Refrigeration

PD: Pressure Drop (kPa)

R: Refrigerant

RC: Refrigeration Capacity $(\mathrm{kW})$

$\mathrm{T}_{\text {dis: }}$ Discharge Temperature $\left({ }^{\mathbf{C}} \mathbf{C}\right)$

Te: Evaporation Temperature in $\left({ }^{\mathbf{}} \mathbf{C}\right)$

VRC: Volumetric Refrigeration Capacity $\left(\mathrm{kJ} / \mathrm{m}^{3}\right)$ Greek 


\section{REFERENCES}

[1] Y.Ould-Amera, S.ChikhaK.Bouhadefa, G.Lauriatb. Forced convection cooling enhancement by use of porous materials. International Journal of Heat and Fluid Flow,19(3), pp. 251-258, (1998).

[2] R. Cabello, E. Torrella, J. Navarro-Esbri. Experimental evaluation of a vapor compression plant performance using R134a, R407C and R22 as working fluids. Applied Thermal Engineering,24(13), pp. 1905-1917, (2004).

[3] Lee H-S, Son C-H. Condensing Heat transfer and pressure drop characteristics of hydrocarbon refrigerants. Int J Heat Mass Transfer,49, pp. 1922-1927, (2006)

. [4] Zhang X, Zhang X, Chen Y, Yuan X. Heat transfer characteristics for evaporation of R417A flowing inside horizontal smooth and internally grooved tubes. Energy Conversion Management, 49(6), pp. 1731-1739, (2008).

[5] A.S.Dalkilica and S. Wongwisesb. A performance comparison of vapor compression refrigeration system using various alternative refrigerants. International Communications in Heat and Mass Transfer, 37(9), pp. 1340-1349, (2010).

[6] Abdullah A.A.A. Al-Rashed. Effect of evaporator temperature on vapor compression refrigeration system. Alexandria Engineering Journal, 50, pp. 283-290, (2011)

[7] A.Baskaran, P.Koshy Mathews. A Performance comparison of vapor compression refrigeration system using various alternative refrigerants. International Journal of Scientific \& Engineering Research, 3(10), pp. 1-7(2012).

[8] B.O. Bolaji, D.O. Kom olafe, F.O. Ajayi and E. Akinnibosun. Performance Assessment of Three Eco-Friendly HydroFluorocarbon and Hydrocarbon Refrigerant Mixtures as R22 Alternatives in Refrigeration Systems. Middle-East Journal of Scientific Research, 23 (8), pp.1677-1684, (2015).

[9] Mitesh M. Deshmukh, K.V. Mali. Performance Comparison of R22 refrigerant with Alternative Hydrocarbon Refrigerants. International Journal on Theoretical and Applied Research in Mechanical Engineering (IJTARME),4(2), pp.17-21, (2015)

[10] Zhang X, Zhang J, Ji H, Zhao D. Heat transfer enhancement and pressure drop performance for R417A flow boiling in internally grooved tubes. Energy. 86, pp. 446-454 (2015).

[11] A. Baskaran and P. Koshy Mathews. Investigation of New Eco-Friendly Refrigerant Mixture Alternative to R134a in Domestic Refrigerator. Australian Journal of Basic and Applied Sciences, 9(5), pp. 297-306, (2015).

[12] Sharmas ValiShaika, T.P. Ashok Babub (2017). Theoretical Performance Investigation of Vapor Compression Refrigeration System Using HFC and HC Refrigerant Mixtures as Alternatives to Replace R22. Energy Procedia, (109), pp.235-242, (2017).

[13] R. S. Powade, A. A.Rane, A. D. Rane, O. S. Sutar, V. S. Bagade. Performance Investigation of Refrigerants R290 and R134a as an Alternative to R22. International Journal for Research in Applied Science \& Engineering Technology (IJRASET),6(4), pp.46684675, (2018).

[14] Mohammad Tarawneh. Performance study on the evaporation and pressure drop of low-temperature refrigerant blends in porous media. Heat Transfer-Asian Research,48(4), pp,1381-1398 (2019).

[15] Mohammad Tarawneh. Combined Effect of Using Sub-cooling Regenerator and Porous Evaporator on the Performance of Refrigeration System. International Journal of Innovative Technology and Exploring Engineering (IJITEE), 8(8), pp.1262-1268, (2019).

[16] Bitzer. Refrigerant Report. Bitzer International,15th Edition, 71065 Sindelfingen, Germany, (2012).

[17] ASHRAE Hand Book (chapter 30. Available at: http://www.tmt.ugal.ro/crios/Support/IFPC1/Misc/SI_F09_Ch30.pdf, (2009).

[18] Thermodynamic Properties of DuPont(tm) ISCEON(R) MO79 (R-422A).

https://www.refripro.eu/fic bdd/fluides pdf fichier/11630964830 ISCEON MO79.pdf 